\title{
Reflections on the Cultivation of Pupils' Ideal Personality by Sinology Learning Education
}

\author{
Qiai Huang \\ China Jiliang University
}

\begin{abstract}
While promoting the sinology education in primary schools, we also need to think about the following important questions: are the primary school students old enough to receive sinology education? What are the specific goals of children receiving sinology education from an early age? How to conduct correct sinology studies? How to perform education training? By means of literature analysis and comparative method, this paper puts forward some visions on the goal of sinology education and the cultivation of ideal personality in primary schools. It is concluded that the main training methods of sinology education in primary schools include reading classics, combining teaching materials, learning piano, painting and calligraphy. That is, we can resort to traditional culture to cultivate students' ideal personality.
\end{abstract}

Keywords-Sinology education; Ideal personality; Classics of sinology studies; Personality cultivation

\section{INTRODUCTION}

As a big country with 5,000 years of splendid civilization, excellent traditional culture is our country's most valuable asset After the Western Learning and the Eastern Chinese Studies, people's discussion and attitude towards traditional culture have undergone many changes, and the term "national studies" has also been born. Under the definition of modern education, it refers to Chinese culture and scholarship. In many people's views, sinology studies only include classical Chinese and ancient poetry, but in fact, sinology learning is based on the pre-Qin classics and the philosophers of the philosophers. It covers the Han and Han Dynasties, the Wei and Jin Dynasties, the Sui and Tang Dynasties, the Song and Ming Dynasties, and the Ming and Qing Dynasties. The Qing Dynasty and the outstanding pre-Qin poetry, the daughter-in-law, the Six Dynasties, the Tang and Song poetry, the Yuan opera, the Ming and Qing Dynasties and the history and other complete cultural and academic systems. Sinology learning is the ancestors left to us, and it is the greatest wealth we can leave to our children and grandchildren. In recent years, sinology education has been promoted. Many parents have sent students to the national school class, and many schools have also launched a nationality interest class. The purpose is to let children learn sinology education from a young age and accept the influence of excellent traditional culture. However, it also led to a series of discussions: Is the age of primary school students suitable for the teaching of Chinese classics? Is the content of the Chinese language class really a national study? Let the children receive the national education from a young age, is it a follow-up or a new training goal? Some research observations, I found that most of the interest classes in the national school classes and schools for primary school students are based on the classics of sinology studies, such as "Three Character Classics", "Hundred Family Names", "Thousand Characters", "The Analects of Confucius", etc., supplemented by calligraphy, Sinology painting, traditional etiquette and other teaching content. The choice of these textbooks is in line with the content of sinology teaching, but it is still unclear whether the interpretation of teaching staff is in line with the original meaning and whether the teaching method is reasonable. In particular, some educational institutions and some parents are too eager for quick success, regardless of the original starting point of teaching, but simply let the children recite the ancient Sinology, and do not seek any solution. Or, when the child has not systematically studied the knowledge of classical Chinese, he begins to let students write classical sinology. These are all to attract attention and earn a gimmick. In this way, it will only make children feel resistant, and it will also cause many misunderstandings and criticisms on sinology education. Therefore, before entering the national school class, parents and teaching staff should clarify the teaching objectives and formulate the correct teaching methods according to the goals. The following is my thoughts on the cultivation of the ideal personality of primary school students in sinology education.

\section{THE PURPOSE AND IMPORTANCE OF PROMOTING SINOLOGY EDUCATION IN PRIMARY SCHOOLS}

Moral education is a very important part of the education of sinology culture. Since ancient times, the mainstream thoughts represented by Confucianism have strict and specific requirements for human virtues, Such as: "the ancient desire to be clearly virtuous in the world, the first to rule the country, the first to bring his family; those who want to follow his family, the first to cultivate their moral integrity; those who want to cultivate their moral integrity, first straighten their minds...The heart is then the body is repaired, the body is repaired and then the home is integrity, the home is integrity and then the country is ruled, the country is ruled but the world is flat after that. (Doctrine of the mean) ". And other schools of thought, such as:" on the good if the water, water good benefit of all things without struggle, in the public evil, so several in the road. (Tao de Jing). " " Virtue and inaction and no thought "(Lao Zi) and so on. The wisdom of the ancestors not only flashes the radiance of reason, but also highlights the beauty of human 
morality. Therefore, for the elementary school education of primary school students, the core should be moral education. The ideal personality of cultivating students should be the main goal of sinology education.

Why is it important to let primary school students receive sinology education from an early age? First of all, this is in line with the law of children accepting the enlightenment of sinology studies. Primary school, especially in the lower grades, is like a blank piece of paper, in the golden stage of absorption and memory in life. The humanistic education accepted in this period will form the background of his life. The formation of outlook on life and values has an important impact. Before entering the upper grades, the primary school students' learning pressure is temporarily small, and they can have extra time and energy to carry out after-school interest learning activities. Therefore, letting children receive sinology education in primary school helps to cultivate their interest in sinology studies. Interest is the best teacher for children to learn, without the pressure of study and utilitarian color, to create a good atmosphere of sinology learning, to enable children to have a deeper understanding of the traditional culture of the motherland, to add a deep tradition of traditional culture to his life. color.

Secondly, the understanding of classical classics in sinology education is also beneficial to students' study of humanities and history and other humanities subjects. The improvement of language literacy is inseparable from its own accumulation and broadening of its horizons. Sinology education can help children to increase the accumulation of words and literature, improve their reading ability and expressive ability. By feeling the rhythm of ancient poetry and harmony, the picture is vivid, the charm of Chinese language is felt, the appreciation ability is improved, and in the study, the mind is cultivated and the humanities are cultivated. spirit. In the traditional culture, the classics about diligence and good thinking, such as "quick and eager to learn, and not ashamed to ask questions, that's why they call it 'Wen'."To learn without thinking is labour lost; to think without learning is perilous. " "being quick and ready to learn, and not ashamed to ask questions below, is what we callWen". "A wise man is worse than a good man, and a good man is not better than a happy man.

"(Analects of Confucius)mind and eager to learn, not to be ashamed to ask, is also called "text"." "Study without thinking is ambiguous, thinking without learning is ambiguous." "Min and eager to learn, It's not a shame to ask, it's called "text".", "Those who know are not as good as those who are good, those who are good are not as good as those who are happy." (The Analects of Confucius) can also let children develop good study habits in the eyes and ears. To be knowledgeable, deliberate, clear, and limp.

Moreover, the education of sinology culture is more conducive to students to understand the history of their motherland, to understand the glorious deeds of the great sages, and to understand the splendid civilization of China over five thousand years. Let students naturally produce strong patriotic feelings and pride in national culture. In the long run, it has a positive and positive effect on the inheritance and development of the fine traditional culture of the nation and the enhancement of national culture self-confidence. A country, only with cultural self-confidence, can inherit and develop its own excellent cultural traditions, and is full of self-reflection and discarding spirit. The young people are the future and hope of the nation. Learning sinology studies from an early age will help them strengthen their spiritual strength and avoid the loss of the wave of pluralism under the background of globalization and become the inheritor of excellent traditional culture.

\section{THE PURPOSE AND IMPORTANCE OF IDEAL PERSONALITY TRAINING IN PRIMARY SCHOOLS}

In the social news in recent years, the accidents concerning "bear children" have emerged in an endless stream, and the trend of development has become more and more intense, and the negative social impact and property losses caused by it have become more and more serious. How to avoid this phenomenon has become an urgent problem to be solved. We all know that the cultivation of good behavior habits of children should be started from an early age. However, only restricting the child's behavior singly, but not correctly guiding the child and ideology and moral education, can not solve the fundamental problem. Because ideology and morality are not in the scope of entrance examinations, many elementary school ideology and morality education courses have basically become furnishings, and they have been occupied by the main subjects for a long time, and parents often cannot control their moral behavior well and educate their children. It is impossible to talk about it, and love it. In society, the bad comments on "bear children" are increasing. People attribute the reasons to the education problems of families and schools, but they cannot provide solutions. In the long run, there will be more and fewer instances of "bear children". This must be brought to the attention of the society, and moral education for primary school students cannot be ignored. And sinology education can add help to this goal.

The so-called ideal personality, as far as the individual is concerned, is the realization of the pursuit of life and the realization of the ideal of value. It is the self-improvement of personality; as far as a nation is concerned, the spiritual temperament and the intrinsic value orientation of the nation are the self-shaping of the national character. China's ideal personality is based on the moral pursuit of virtue and perfection, and strives to achieve a high spiritual state of mind and a free spirit, especially the pursuit of the value of human life and the ultimate concern of the meaning of life. Using traditional sinology education can help primary school students to reshape morality and cultivate ideal personality. In the primary school stage, the ideal personality cultivated by the students is: a spirit of patriotism, an enterprising spirit of selfimprovement, a good moral character and a high sense of social responsibility, a filial piety, respect for the teacher, honesty and trustworthiness, and a spirit of diligence and good thinking.

In the education of sinology learning, students can feel the great patriotism of the ancestors before the fate of their own destiny through the "life and death of the country, and the sorrows and sorrows of sorrows and sorrows." Feel the spring mud and protect the flowers. Feel the poet's heart and 
dedication to the patriotic spirit. To feel the poet's deep hope for national unity by the " On the day when the army of the Song Dynasty regained the Central Plains, don't forget to tell me the spirits of the undead at the sacrifice. ". To appreciate the great rivers of the motherland from "Water flows straight down from a height of three thousand feet. It is suspected that the Milky way falls into the mortal world. " "Mount Tai, how magnificent you are, you are tall and straight and green and straddle Qilu. The Creator has concentrated beauty and wonder for you, and your high peaks divide the north into the south and the morning into the evening. ", "In boundles s desert lonely smokes rise straight; Over endless river the sun sinks round.". Through familiar reading, "You can't be without Hony, and you have a long way to go." "Tian Xingjian, the gentleman is selfimproving." Understand that people should be self-reliant. From "the worries of the world, the joy of the world, and the joy of the world." "And you can enjoy the social responsibility of the world." At the same time, the children will also be moved by the allusions of "Huangxiang Wen $\mathrm{Xi",}$ "Immediately Asking for Ice", "Shelving the Father" and "Chengmen Lixue", and understand the truth of respecting parents and respecting the teachers. From "'", you can also be at the beginning of the human race, the nature is good, the sex is similar, the $\mathrm{Xi}$ Xiangyuan is far away, and the "Kong Rongrang pear" "has not been desired, do not apply to others"Must have a neighbor"I am the three provinces of my body: for people to seek and not loyalty? Do not believe with friends? Do not pass on?" "Light promises must be wise, more difficult and more difficult" in the sense of maintaining good, honest, trustworthy Quality. In the "learning without thinking, then thinking, not learning, then" "black hair does not know how to learn early, white first regrets reading late" "Shushan has a road to be a path, learning the sea without a hard work" Zhong Fen began to study and learn the hard spirit of "small squirting snow" and "searing the wall".

\section{THE USE OF TRADITIONAL CHINESE EDUCATION TO CULTIVATE THE IDEAL PERSONALITY OF PRIMARY SCHOOL STUDENTS}

The use of traditional sinology education in daily education has the following points.

\section{A. Extend language teaching in class}

In the class, the teacher can combine the textbooks, start with the classical Chinese and ancient poetry in the textbooks, and lead the students to understand the characters and story background in the classics. The first step is to learn ancient poetry from the perspective of literature, and use ancient poetry to let students understand the rhythm, rhyme, metrical poetry format, lyrics and other knowledge points, and let the students summarize the theme of the most poetry on the premise of understanding poetry. Grasp the poet's emotions, appreciate the "poetry eyes" and "words" in the poems, and imagine and express the pictures depicted by the poems. In the second step, you can also combine the ancient poetry background to let students understand the history at that time. This is important because there is no history lesson in the primary school. According to the younger characteristics of the students, the history can be introduced but relatively detailed, so that students can enter the world of ancient poetry, instead of blindly teaching. After class, you can use some related exercises to help students consolidate the knowledge of classical Chinese and ancient poetry. And guide students, accumulate celebrity allusions, etc. as a writing material to improve their ability to express and write. Based on classroom teaching and the expansion of materials in the class, it is relatively easy for students to learn. Therefore, to improve students' interest and learning ability in sinology studies.

\section{B. Extracurricular students are allowed to read and accumulate classics of sinology studies}

The study of humanities subjects must be accumulated over a period of time, and the cultivation of ideal personality is even more inseparable. Therefore, students should be encouraged to accumulate and read sinology classics in their spare time and when students are energetic. Students can develop their own study plans and develop good study habits. And the study of sinology classics can not only stay in the meeting, but should be like the expansion of the class, and carefully understand the classic historical background. Students can use tools, information books, or the Internet to find rich historical materials to help them understand the authors and understand the historical figures in the allusions, so as to more deeply understand the characters' emotions and grasp the themes of sinology classics. For example, if you read the famous sentences in the classics such as The Analects of Confucius and Mencius, you should properly understand the historical background of the time, understand the era of the most brilliant and contending, and understand the hundred flowers of the philosophers and understand the core of Confucianism. Ren, righteousness, courtesy, wisdom, and faith." In reading Hutian August is the snow and The scenery is different in the autumn, understand the vastness of the border desert, the hard living environment of the warriors, their homesickness and their homesickness. The feelings of the Weiguo. In the reading of "When Wohe Day, sweat dripping down the soil" and "Don't know the heat, but the summer is long." Feel the bitterness and pain of the working people at the bottom of the feudal society. In the lingering classics, let students know and understand the long history of the Chinese nation, rich cultural heritage, and let students feel proud of their national civilization from the heart. Under the nourishment of humanistic classics, we have a more perfect and independent ideal personality.

\section{Students are allowed to develop the habit of independent thinking in their studies}

To use sinology education to cultivate ideal personality, we must not only accumulate profound cultural heritage, but also learn a large number of traditional excellent cultural classics. What is more important is to let students learn to think independently. As students learn to access the content of the text, they can be guided to ask their own questions and learn to draw conclusions using a variety of materials and basic research methods. For example, while teaching students to read "Selling Charcoal", students can also think independently about "Why are you selling charcoal's poor clothes, and worrying about the cold?" This will not only make students feel the text content. It is more profound, and at the same time, it also allows students to understand the history of the hard- 
working life of the working people at the bottom of the feudal society under the oppression of those in power. They can also divergent thinking and contact the Pity for the Peasants and the Water Margin, have a deep understanding of the famous peasant uprisings in Chinese history, and feel the spirit of the ancestors who are unwilling to oppress and bravely resist. This kind of learning method is far more helpful than the rote memorization to help students digest knowledge and sublimate their moral thoughts and feelings.

\section{Develop children's interest in traditional cultural hobbies such as calligraphy and Chinese painting}

Qin, chess, books, and paintings as the "four friends of the literati" of the ancients can still represent the cultural qualities of people in today's society. These four skills are also very suitable for children of the primary school age to receive enlightenment and can develop into hobbies. By learning these traditional techniques, students can be influenced by culture and art in the atmosphere of traditional culture. The traditional culture is also diversified and comprehensive, which is also conducive to students' self-cultivation.

\section{E. Teachers and parents make the right guidance}

Both teachers and parents are educators in the educational environment of children. Children receive sinology education in primary school, and both teachers and parents play an important role. Children at this stage are in a period of eagerness to imitate the words and deeds of adults. Therefore, any language behavior of teachers and parents will have a great impact on children. Teachers should adopt correct personality training methods, subdue students with wisdom, emotionally affect students, and let students fully exert their autonomy in teaching, and actively guide them appropriately. Parents, while creating good educational conditions for students, should also strictly demand themselves. As a child's moral role model, parents should set an example for their children.

\section{CONCLUSION}

In short, in today's competitive environment, people with ideal personality can better realize their own life value. Therefore, the cultivation of ideal personality is very important, especially in the primary school stage. This is the period in which people form a world outlook, a outlook on life and values in their lives. The correct use of sinology education can allow students to gradually cultivate their ideal personality in a subtle way. It is true that the cultivation of an ideal personality is not a one-off effort. We must continue to explore the role of sinology education and add momentum to the growth of the motherland's flowers.

\section{REFERENCES}

[1] Zhao Shiping. A preliminary study on the theory of Confucian personality [J].Journal of Chongqing Normal University (Social Science Edition), 2004(06):37-42. (In Chinese)

[2] Xu Yan. How to infiltrate Chinese education in primary school Chinese teaching[J].Weekly,2014(12):128. (In Chinese)

[3] Qin Jinlei, Meng Qingli.Investigation and countermeasures on the status quo of organic integration of Chinese education and primary school curriculum [J]. Middle School Students' Guide: Teaching Research, 2013 (22). (In Chinese)

[4] Dou Shina. Research on the status quo, problems and countermeasures of primary school education in primary school students [D]. Liaoning: Liaoning Normal University, 2014, 5. (In Chinese)

[5] Yang Qian. The Ideal Personality and the Way of Adults - Reconsideration of Confucius and Mencius' Personality Theory [D]. Morality and Civilization, 2004(4): 23-26. (In Chinese)

[6] Xu Fang. Expanding the text content and using the traditional cultural enlightenment textbook--A preliminary study on Chinese language education in primary school $[\mathrm{J}]$. The Science Education Article Collects,2015(32):90-92. (In Chinese)

[7] Marklin. The Education of National Studies in Primary School Chinese Teaching[J]. China External Education Journal, 2017(11):15-15.( In Chinese)

[8] He Wei. Feng Youlan Feng Qi's ideal personality theory comparison[J]. Tianjin:Nankai University Press.2012.5. (In Chinese)

[9] Wang Guizhen. Teaching of Ancient Poetry and Prose in Middle School and the Creation of Ideal Personality of Middle School Students [D]. Yunnan: Yunnan University, 2017. (In Chinese)

[10] Zhang Ling. Strengthening traditional culture education and cultural inheritance in primary school Chinese education [J]. Caizhi, 2009 (15): 33+46. (In Chinese) 